\title{
Historein
}

Vol 8 (2008)

Performing Emotions: Historical and Anthropological Sites of Affect

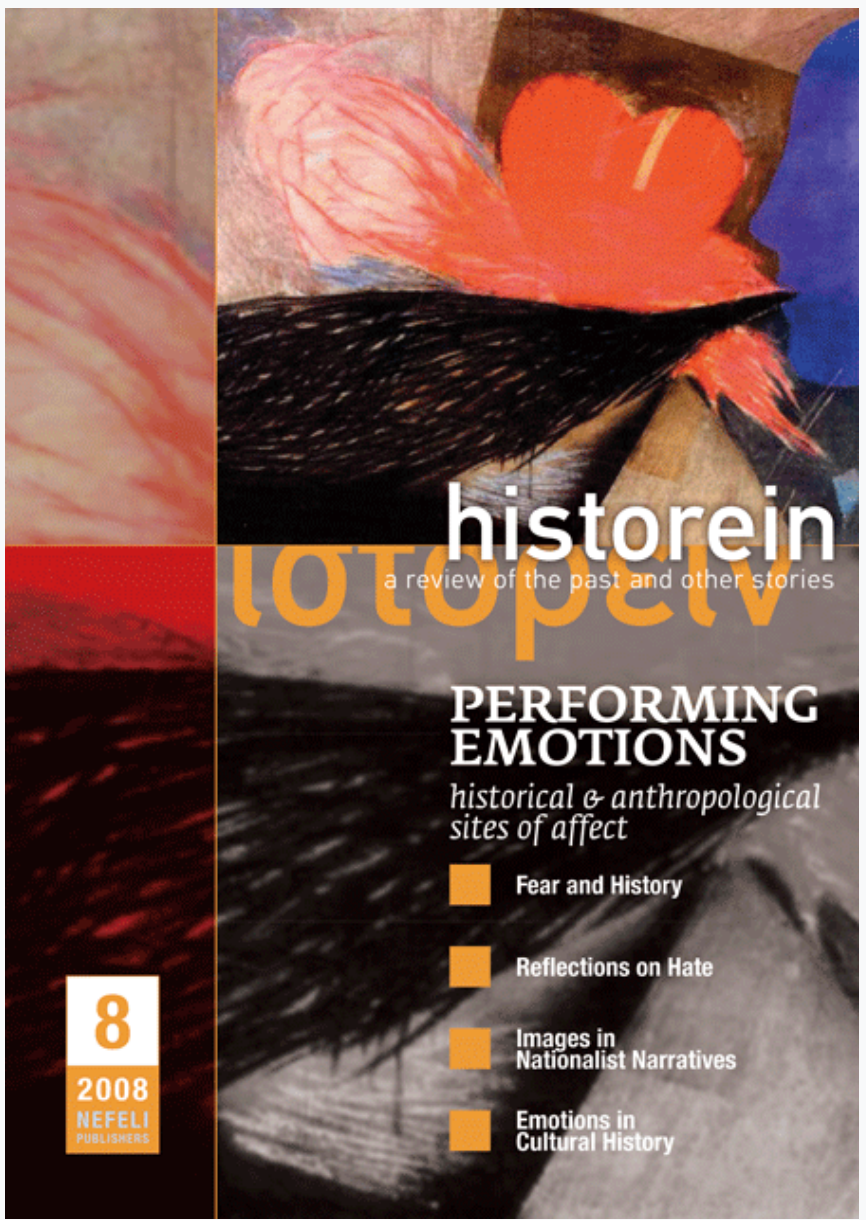

\section{Fear and History}

Peter N. Stearns

doi: $10.12681 /$ historein.34

Copyright $\odot$ 2012, Peter N. Stearns

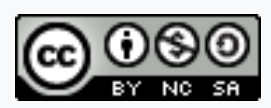

This work is licensed under a Creative Commons Attribution-NonCommercialShareAlike 4.0.

To cite this article:

Stearns, P. N. (2009). Fear and History. Historein, 8, 17-28. https://doi.org/10.12681/historein.34 
The following passage is one of the most famous in American history, from President Franklin Roosevelt's inauguration address in 1933: "Let me assert my firm belief that the only thing we have to fear is fear itself - nameless, unreasoning, unjustified terror which paralyses needed efforts to convert retreat into advance. In every dark hour of our national life a leadership of frankness and vigour has met with that understanding and support of the people themselves which is essential to victory."

Roosevelt's passage built on nineteenthcentury approaches to fear, including the statement by the intellectual Henry Thoreau, "nothing is as much to be feared as fear". The passage, and the larger tradition of emotional standards, forms an intriguing contrast to more recent American formulations, in which leaders have attempted to encourage and manipulate fears and have systematically avoided opportunities to urge Americans not to be needlessly afraid. This contrast, between the 1930s and the present, reflects different threats: economic depression versus international terrorism. But it also reflects significant changes in emotional standards themselves, which can only be explored through the still-new but promising field of emotions history. The same exploration invites consideration of comparative issues that go beyond the single national case.

This article comes in two, though related, parts. First, I want to discuss American fear, on which I have just completed a research

\section{Fear}

\section{and}

\section{History}

\section{Peter N. Stearns}

George Mason University 
project and which is a topic of great political and indeed international interest. My argument will be that, for several assignable reasons, many Americans have developed an unusual openness to fear and an unusual - at least by the standards of some other societies or those of the nation's own past - willingness to seek to voice fears and to try to use fear in motivation. Second, however, I want to turn to a broader historical and comparative picture to ask some questions about the history of fear more generally, at least in Western society, and about the desirability of a truly international project on the subject. This kind of project would be unprecedented, but it is invited by a series of recent works on this key emotion as well as by the need to put particular cases, such as the United States, in a clearer comparative context. How much fear is a normal part of social functioning? Is fear, as some have argued, the dominant modern emotion, and, if so, how can we explore this - or even test the claim - historically?

\section{American fear}

By 2006-7 it had become quite obvious that a variety of actors were deliberately fanning public fears in the United States for particular purposes. Most blatantly (and this had indeed been true in 2004 but was simply not as widely perceived), Republican leaders were pressing a fear argument against Democratic candidates, urging the need to remain vigilant against terror. The manipulative efforts became so transparent that even popular comic strips and television satirists began to weigh in.

But American fear issues ran deeper than this, so that a further exploration is not merely belabouring the obvious. Already in the late 1990s a significant sociological study had concluded, with convincing evidence, that Americans were expressing intense fear concerning a host of problems that were either nonexistent or exaggerated, creations in part of the emotion itself. Barry Glassner and others showed, for example, how self-reported fears of crime mounted in the 1990s even as actual crime rates dropped; perceptions, based in part on the plethora of crime-soaked television shows, helped fuel a false reality and an acute emotion. ' Other distortions were interesting. Americans readily believed in a high rate of children's abductions by strangers, whereas in fact the phenomenon was extremely rare; an extreme case, in 2007, saw a middle-class Florida couple forbid their teenage children from walking down the driveway to pick up the mail, lest they be snatched. Another revealing instance involved the celebration of Halloween, when many American children traditionally go house-to-house to ask for candy, in what is called trick or treat. Dire reports spread in the 1980s of children who had received poisoned food or food with concealed razor blades. In fact, none of this actually happened. But the fear result prompted massive retrenchment on trick-or-treating, in the form of restricted hours and extensive parental supervision. Fear won, not just at the time but for at least two ensuing decades.

Excessive fear greeted the terrorist attacks of 9/11. Qualitative evidence is strong. Many Americans stopped using airplanes for months, and some extended this to busses and trains; or when they took public transportation, some reported being "scared, so scared" - even in parts of the country quite distant from the attacks. A waiter in a Midwestern town noted that "nobody wanted to do anything more" - and this thousands of miles from the attacks and six weeks later. 
A business traveller described how people were "frightened as never before". ${ }^{2}$ A psychologist adds that many Americans had become afraid of situations that were in fact quite secure, as fears of terrorism replicated the tendency for emotional overextension that had applied to other subjects in the 1990s.

A more purely impressionistic expression of fear involves a surprising capacity for hyperbole, even years after the event. An American art gallery, displaying European medieval art, compares the Black Death to 9/11 - that is, a 25 per cent population loss compared to the deaths of about 3,000 Americans. A book review comments on author Salmon Rushdie's life under threat of assassination, but then notes that this is now how all Americans have to live.

Obviously, fear of this sort has had measurable consequences, though of course one can debate what reflects excessive emotion and what constitutes prudent realism. Far more than other countries, the United States now surrounds public buildings with massive, often quite unattractive barriers. Airport security requirements escalate, with one result that passengers to the United States are distinctively monitored, compared to those heading elsewhere and because of US government requirements, in airports like Frankfurt and Charles de Gaulle. Screening of foreigners, already severe, can become almost punitive; foreign scholars or students, returning home from the United States on brief vacations, sometimes found they could not get back to their jobs or schools because of heavy visa regulations. For several years, the federal government virtually invited bouts of public fear with a system of colour-coded warnings, designating levels of threat but never allowed to be anything less than frightening; while these warnings were supposed to trigger particular levels of police activity, they had little public purpose other than emotional incitement. Equally interesting was the impact of fear on voting patterns, at least through the 2004 presidential elections. A group of middle-class mothers deeply invested in their children including their sponsorship of sports participation - hence a common earlier designation, soccer moms - now shifted to support of the Bush campaign explicitly on grounds of their new security concerns. Here was another sign of durable and consequential fears, and the strong element of personalisation. How much, finally, of American willingness to support a globally unpopular attack on Iraq resulted from public fears is open to question, but emotion played some role and perhaps a considerable one.

It is possible to try to measure the fears that greeted $9 / 11$, and long persisted, though of course the effort lacks full scientific precision. Two kinds of measurements can be suggested. The first is comparative. American emotional reactions suggested far deeper and wider-spread panic than those that responded to the attacks on commuter trains in Spain and in Britain later on, or those that respond to suicide bombings in Israel. In the Israeli case, an interesting specific study shows how few Israelis change their use of busses after an attack, and not at all outside the immediately affected routes; the contrast with American national abandonment of planes for several months is striking. Spaniards reacted to the Madrid bombings with a few hours of clear public disorientation, but then massive evening demonstrations, in public - something that more privatised Americans did not venture at all. Britons largely evoked a stiff-upper-lip reaction in 2005, using an established national model of dismissive courage. Of course some people were scared in fact, not just at the time but for weeks after, but the public mood was quite clearly defiant. The 
only organised effort to stay out of public places after the London attack came from American military bases, where personnel were confined to quarters until British annoyance prompted a reversal of policy. Of course these reactions occurred after the American example of greater panic and were partly designed to show contrast. And of course they involved distinctly less loss of life and less dramatic visual symbols of devastation. The comparison is admittedly imprecise; it may nevertheless be revealing to a point.

The second demonstration is historical, in contrasting American recorded reactions after Pearl Harbor to those after 9/11. An interesting interview project within weeks of the Pearl Harbor attack, with detailed conversations with over 200 ordinary Americans all across the nation, including one specific question concerning fear, elicited virtually no expressions of the emotion whatsoever. Only one man used the word, but in discussing being afraid that the economy might be disrupted in ways that would adversely affect his family. Otherwise, Americans expressed great confidence that, despite the lack of preparedness, their government would be able to handle the problem. Reminiscences from the period show the same emotional nonchalance. One man describes how he and his family were out for a Sunday drive when they heard the news. They immediately headed for home and did feel disoriented and panicky for an hour or so. But by the time they got back they were calm, confident here too that the nation could handle the crisis.

Obviously, there were fears - on the West coast, fears that among other things would lead to the movement to intern Japanese Americans. But even a mood that encouraged public expressions of calm resolve was itself interesting. In fact, American responses to Pearl Harbor were quite similar to British reactions to bombing attacks and later to the 2005 terrorist raid; but 60 years later Americans did not remember their earlier precedent, and displayed a very different emotional response instead.

Evidence similar to the Pearl Harbor interviews, including stories spontaneously submitted to a 9/11 historical website, demonstrate the frequency of fear reactions, even when no emotional question was explicitly raised at all. A common response: I remember feeling "what if we're next? What if that bridge is next? What if I personally am next?" References to terror, utter panic, months of sleeplessness abounded. This was a far different emotional response from the one that had greeted the Japanese attack 60 years before.

Caveats are obvious. First, I am deliberately using contemporary evidence to frame a historical explanation, to which I will soon turn. I admit that this is not too common in our discipline, but I think it should be encouraged and offer no real apology. In fact, I think we should extend this analytical ambition more widely. Second, and more to the point, I admit that Pearl Harbor and 9/11 were different, just as 9/11 and the Madrid train bombing were different. While almost as many people died in Pearl Harbor as in 9/11, the symbolism was much less rich, the opportunities for media repetition far less immediate. Hawaii was far away, not yet a state; and most of the deaths were military. There was concern that invasion of the continental United States might follow, or that German or Japanese bombs might reach it - so there was some opportunity for a wider emotional response of the 9/11 type, but the differences in situation and in media availability have to be granted. 
Still, this is not a totally flawed historical laboratory. When the apparent change in emotional response over time is added to the apparent emotional difference between Americans and some others in response to terrorism, and then to the other evidence of excessive or misplaced American fears even before $9 / 11$, there is at least a potential situation to be explained, beyond the daunting facts of $9 / 11$ in themselves.

A common explanation, voiced by many Americans at the time, involves a national innocence. Major wars had avoided American soil since 1865. Americans lacked the experience of Britons or Spaniards, or obviously Israelis, so their naïve panic, though distinctive in this rendering, was understandable. And perhaps so, to an extent. But the nation had experienced frequent war, and Cold War fears; terrorists had struck in Oklahoma City and often at American targets abroad, including the African embassies; and innocence would not explain the other excessive fears before 2001.

So, again admitting that there is no foolproof means of showing that reactions to $9 / 11$ went beyond objective necessity and that there is therefore need for more nuanced explanations, I would submit that there is at the least a strong case to be made. Changes had occurred in American emotionality that must be assessed - changes that also help explain comparative differences in contemporary reactions - and in fact a causal pattern can be demonstrated. ${ }^{3}$

The basis for distinctive reactions to fear began to take shape in new socialisation patterns recommended from the 1920s onward, as evidenced, for example, by new childrearing manuals. These shifts did not immediately take hold. They did not, as we have seen, impact on Pearl Harbor reactions; they did not inform Franklin Roosevelt's famous 1933 speech about the only thing that need be feared was fear itself - a speech clearly based on older emotional values. For children, however, experts increasingly recommended that fear as an overpowering emotion that must be sidestepped wherever possible, rather than confronted. New psychological inputs into American childrearing reflected research that showed how children inevitably harboured irrational fears. Parents must help them overcome through constant reassurance. Unnecessary fears must also be avoided. Children should not be urged - as had been commonly recommended in the nineteenth century, particularly for boys - to overcome fear with courage. This was simply too stressful, and risked overpowering a child. The wise parent avoided fear situations for children wherever possible: to take a prominent example, he or she bypassed fear of the dark by installing night lights; and the same parent rushed in with comfort and possibly distracting bribes when fear did occur.

This socialisation pattern would continue and intensify, amid passing shifts in expert fads, through the twentieth century. It was predicated on the twin belief that children were emotionally fragile; particularly where intense emotions like fear or grief were concerned, and that parents and other adults should be able to minimise risk. Early twentieth-century experts indeed trumpeted their sense that, in a proper modern world, fear and risk should be banned, in contrast to the bad old days. Behaviourist psychologists like John Watson translated similar optimism into specific childrearing recommendations, again on the assumption that careful parental arrangements should be able to eliminate childish fear. The result, of course, was a socialisation pattern 
that might give children relatively little experience in facing fears on their own, as opposed to expecting quick reassurance and remediation and learning that fear was an emotion that could be legitimately resented, its causes rejected as inappropriate, its sources exaggerated. The result, in other words, could be the same kind of reactions that would underpin reactions to intrusions like $9 / 11$ or the exaggerated perceptions of risk that have been described for the 1990s. In an ideal world, many Americans were taught, serious danger should not exist, but where lessthan-ideal circumstances were encountered many were ill-prepared. Risks seemed riskier in a culture that urged that they should be arranged away.

This source of American fear in new patterns of socialisation and expert advice was compounded, from the 1940s onward, by unusual national exposure to repeated foreign threats and crises. There is no need to rehearse a familiar history here. The tensions of participating in the Second World War, though not as great as in the actual war zones, were then compounded by Cold War scares amid the nuclear threat. Specific crises like the Cuban Missile Crisis generated panicked rhetoric. The toll on national emotional nerves is not easy to calculate, but in a culture that disliked fear the challenge was unmistakable. The toll showed particularly in the growing propensity to expect a major threat from the external world and to merge new problems with old. The Bush administration's repeated assertions - partly manipulative, but partly sincerely credited - that Saddam Hussein could be compared to Hitler or Stalin, or that the so-called war on terror was just simply another instantiation of the Cold War with a battleground stretching from the Mediterranean to the Pacific, show the connections very clearly. External threat became an expected constant, its fear potential a constant as well - which helps explain, along with the new and more general fear culture, the propensity for exaggerated responses and excessive fright.

The third major factor in this causal equation emerged in the 1970s and 1980s, adding to the two factors already accumulating. Media of various sorts began playing up fear as a sales device, for products and political causes and candidates alike. During the bulk of the twentieth century advertisers deliberately stayed away from fear, which seemed consistent with the larger emotional culture: if Americans were becoming increasingly uncomfortable with the emotion, it was dangerous to evoke it in sales. Occasionally merchandisers wondered aloud if an opportunity was being missed, but in general advertisers were cautious. Fear might drive people away. This kind of emotionality was used only if fear could be invoked moderately and then a product introduced that would conclusively deal with the threat. Only 15 per cent of all advertisements between 1920 and the 1950s used fear appeals of even the most careful sort. It was revealing that, in the late 1940s, an initial effort to promote nuclear controls through fear strategies was reconsidered, because the scientists involved worried that overemphasis on threat would antagonise the public and prove counter-productive.

In the 1970s and 1980s, however, tactics changed dramatically. Advertisers realised that precisely because the public was so fear averse, the emotion could draw reluctant attention and win voters or customers. New problems, like AIDS, also help explain the shift. Toilet seat manufacturers, for example, deliberately took advantage of AIDS to sell their otherwise unappealing product, noting that "scare is in the air". IBM, in computers, became known in the 1990s for advertisements based on FUD, or fear, uncertainty and doubt. Political campaigns notoriously began 
to use fears - of crime, of foreign threat, in a trend that obviously found new vigour in the wake of $9 / 11$. As an advertising guru noted in 1998, fear-based entertainment on television now took a back seat to the fears purveyed during the commercial breaks. Then, after $9 / 11$, constraints loosened further: as one public service advertiser claimed, "If you're going to spend cash trying to persuade (i.e., terrify) voters, why waste it on fairness and context. The whole idea ... is to present an issue in stark terms, and never mind if the starkness exaggerates the threat." ${ }^{\text {E Even }}$ weather reports became deliberately more ominous.

The connections could be amazingly farfetched. In the wake of 9/11, a telephone company in Chicago, warning against making bad decisions on service providers, featured a maid in an office complex wielding an axe. A sanitary napkin company cautioned that rival products caused cancer - a totally fraudulent claim, but suitably terrifying. Well-intentioned public service pitches inflated the dangers of bird flu or (many argued) the consequences of environmental change in the same vein. As one industry observer put it, perhaps a bit blandly, "This shift toward a calculated attempt to frighten customers into making purchases is very well timed." ${ }^{\mathrm{5}}$

This media movement obviously helps explain why, particularly in the decades around 2000, Americans became increasingly convinced that their immediate environment, even the neighbourhood, was now menacing, not to mention the wider world. Some analysts, including Barry Glassner, attribute the entire movement towards greater American fear to media manipulations. And in terms of chronology as well as impact, the change in media tone was indeed truly significant. But media manipulation depends as well on audience, and an audience less ready to be disturbed by fear, less eager for risk-free assurances, would not have provided the climate for the media change. Here, the longer-term factors of altered socialisation and crisis-saturation are essential components as well. The entire package, enhanced slightly further by American religiosity and the availability of end-of-the-world rhetoric and the anxieties occasioned by the new millennium, provides historical tools through which current emotionality in this vital area can be assessed and explored.

There is no denying that many Americans continue to value and display courage, though recent memorials suggest a public belief that greater courage lay in the past, with generations like that which fought in the Second World War. The most obvious point is that the changes in emotional climate make it easier for people to declare their fears publicly, and make it harder to criticise those who say they are afraid - a real constraint, given exaggerated beliefs in threat, in the political arena. Sociologist Cas Wouters has pointed out the curiosity of American airmen during the Gulf War, talking openly about how afraid they were. Military tolerance of expressions of fear certainly has increased fairly steadily in the United States, from the First World War castigation of troops traumatised by battle, to greater medical sympathy in the Second World War, to more elaborate efforts to anticipate and even medicate fears today - another sign of significant change.

What the historical analysis does not accomplish directly, of course, is to suggest what to do about a current emotional pattern that is fairly clearly suboptimal. To be sure, the $9 / 11$ fears have by now cooled somewhat and even aspects of the war on terror are being rethought. But the fundamental emotional vulnerability remains, whether the subject is risk calculation or openness to media manipulation. An understanding that this emotional complex is not simply inevitable, 
but is in part a product of history at least opens a door to reconsideration - what was caused during the past several decades can in principle be undone. The growing awareness of crass political exploitation, of the sort that surged forward during the political campaigns of 2006, is another step forward. Ideally, campaign watchdogs can add blatant exaggeration of threat to the list of dirty tricks that requires public reproof. But other factors, including the larger patterns of socialisation, need reconsideration as well. The historian, eager to show how his discipline explains a current phenomenon, can point to further needs but not, in a professional capacity at least, the precise solutions.

\section{Modern fear}

There is another task, however, that is squarely within the purview of historians of emotion, and this leads to my second argument. I have contended thus far that there are some distinctive features to contemporary American fear. The comparison between 9/11 reactions and those in parts of Europe exposed to recent terrorist attack is at least suggestive. My impression is that some of the fear-based media efforts are less salient in other parts of the world, and that socialisation patterns, where fear is concerned, have changed less substantially as well, or at least in somewhat different directions. There is, I believe, an American component to American fear in the contemporary world, as well as distinctive consequences because of the nation's great-power status.

But there is a wider literature in the field that must be acknowledged also that contends that fear has become a predominant emotion in other societies as well. Three claims are particularly striking. First is the work by Tariq Ramadan, one of the leading European Muslim intellectuals, that claims fear as a key motivation among contemporary Palestinians and Arabs (as well as, he notes, among Israelis too). Plausibly enough, without elaborately exploring the emotional cultures involved, he sees opposing but rather similar fears as a key element in Middle Eastern conflict today.

The second approach involves an intriguing study by Christophe Lambert that calls contemporary France la société de la peur. ${ }^{6}$ Highlighting growing anxieties about globalisation and immigration, again without dealing with emotional culture and its historical development in great detail, Lambert claims that fear has become the dominant emotion in French public and political life. This approach may be complemented by another study, by Frank Füredi, that claims that fear-mongering media are a Western, and not simply American, phenomenon. ${ }^{7}$ He coins the felicitous term of fear entrepreneurs in the process. He cites references not just in advertising but in high-culture solicitations, with the Museum of Modern Art in New York mounting an exhibition on the perils of modern living, while an Art Bienniel in France organised a display more simply around the theme of the "art of fear". Füredi goes beyond other commentators also in claiming not only a Western-wide aversion to risk, but an outright increase in phobias - an intriguing historical claim, since it is based on change over time, though not one that he illustrates very precisely. But again the point is this: several plausible observers of Western Europe, or portions thereof, make assertions about a new dominance of fear similar to those, broadly speaking, that Glassner and others, including myself, have ventured concerning the United States. ${ }^{8}$ My points about overreaction to terrorism as a specific United States component might still apply; Euro- 
peans, in contrast, are more fearful (by a small degree perhaps) about immigration and fascinatingly more fearful about genetically engineered foods. So targets might vary comparatively, but basic emotions not, which means that the special explanations I have offered for the United States, and particularly the distinctive changes in socialisation and then the wearing impact of international crises, are partially off the mark.

Then, finally, there is an intriguing recent study, though focused really just on the United States and Britain, that charts new patterns of fear in the twentieth century (though with some confusing asides about the nineteenth) under the general claim that "fear has become the most pervasive emotion of modern society". ${ }^{9}$ Joanna Bourke, an accomplished cultural historian, mentions a host of specific spurs behind this claim, including new killing techniques and new medical concerns - what she refers to as treacherous bodies. The evidentiary base might be regarded as somewhat slender for the larger assertions about fear - not only are merely two countries emphasised, but there is heavy reliance on formal literature. But the assertions are nevertheless fascinating. Another study, strictly American and based heavily on personal experience with anxiety and resultant psychological therapy, makes another claim similar to that of Bourke and Füredi that phobias have greatly increased, which if true, and not simply American, would be a compelling argument about modern fear.

So we emerge with a challenging comparative issue. Specific fears attach disproportionately to specific societies, but is there a wider pattern of more exposure to fear that unites the United States and Western Europe, possibly Islamic society as well, and where beyond? Is it true, quite simply, that fear has become the dominant modern emotion, at least outside a few special cases such as China (but perhaps the same phenomenon would encompass China as well, though some middle-class Chinese, responding to the question on a quite impressionistic basis, do not list current fears so prominently). There is a clear invitation here for a team of emotions researchers, drawn from history but also perhaps sociology and anthropology, to take up these issues more systematically and produce more organised comparative findings. It would be enthralling if a gathering of international scholars concerned with emotion, such as the 2007 Historein conference, took up this charge: what are the current patterns of fear in several key societies, and what has their trajectory been during the past several decades, and has fear moved so generally to an unusually dominant position among emotions overall? I do not know what the results of this kind of inquiry would be, but I think it is truly important to organise a more coherent effort that would go beyond specific national claims, such as mine, Glassner's or (for a different case) Lambert's, but would also do more than assert the dominance of contemporary fear with impressionistic evidence in the fashion of Bourke or Füredi.

There is another issue as well, and a more explicitly historical one. For, in addition to comparative questions, and in many ways preceding them, there is the problem of change over time. Most of the work just discussed assumes or implies that current levels of fear, and the prominence of fear in the modern emotional lexicon, are new. Lambert and Füredi suggest, without careful historical inquiry, that modernity has provoked novel emotions - and this may be the most plausible connecting link among the many studies of fear that have cropped up during the past decade. Glassner's study of the United States, though again not historical, implies new levels 
of fear, though instead of highlighting modernity directly he points to the role of contemporary media. Obviously my analysis of the United States tries explicitly to show that current fears are new - the contrast with Pearl Harbor - and that they exist because of factors new to the twentieth century. Joanna Bourke, finally, seems explicitly to say that the dominance of fear is a novel phenomenon, though she really does complicate her periodisation claim by citing important nineteenth-century fears as well - such as the fear of being buried alive so prominent in Victorian literature, particularly in Britain. ${ }^{10}$

So, how much have levels of fear changed in the twentieth century, compared particularly to the nineteenth? And are the patterns of change similar in several major instances - the comparative question again? But first, what in fact is the fear level in characteristic societies in the nineteenth century, in terms of cultural standards and emotional experiences alike?

We have, to my knowledge, only a few efforts that provide a larger historical perspective on contemporary fear. The first was Jean Delumeau's masterful studies of fear in early modern Europe, where he emphasised the importance of religious-based fear in pre-modern Europe, leading to extensive attempts to use fear of death and damnation for the guidance of adults and the discipline of children alike." Delumeau argued that, with growing secularisation and the Enlightenment, these appeals to fear declined by the late eighteenth century. He further suggested, though only in an epilogue, that fear would return to Western society in the twentieth century around growing fearfulness of the internal bodily processes now responsible for the leading causes of death - processes such as increases in blood pressure, undetected stages of cancer, unnoted deteriorations of heart or arteries that might ultimately lead to a fatal stroke or heart attack. Elements of his argument, at least on the late eighteenth century, might be seen in work on colonial America, where Puritan fascination with predestination and use of death and damnation themes in childrearing gave rise to a more optimistic, moderate strand of Protestantism that urged against uses of fear in raising children and even moved away from beliefs in original $\sin .{ }^{12} \mathrm{~A}$ fear-focused minority persisted, in evangelical Protestantism, but mainstream culture took on different overtones. Without question, arguments against fear played a new and growing role in childrearing literature from the 1820s onwards, though the message caught hold only slowly - reaching American Catholicism, for example, fully only in the 1950s. My own work on the nineteenth-century United States similarly demonstrates the rise of strong cautions against any unnecessary introduction of fear but also a strong reliance on courage and other exercises that would expose older children, particularly boys, to fear so that they could learn to withstand it.

The suggestion here, from several overlapping vantage points, is a bit of a nineteenth-century interruption, in Western culture, between religious-based fears prior to modern times and new anxieties about death that would support a new immersion in fear in the twentieth century. Did nineteenth-century culture provide this kind of oasis, and with what implications for actual emotional experience in groups like the growing middle class or as part of growing up to become an adult? Or have we simply not looked closely enough?

Again, there is an invitation to collaborative scholarship here: can we take a more systematic look at the nineteenth century, in several societies, to see about changes in fear standards, and use this 
in turn as the basis for exploring the nature of twentieth-century departures from nineteenth-century norms and the reasons for these departures? Are the unquestionable changes in twentiethcentury experience and perceptions of death a general prod towards new fears, as Delumeau briefly suggested? Or, again, do we need more refined and carefully comparative historical work?

\section{Underpinning the two overlapping assignments on fear}

The careful look at comparisons in contemporary history to determine whether fear has become the dominant emotion and why, and the similarly sober look at pre-twentieth century patterns, both draw attention to fear as a social variable. Some fears, obviously, attach to any society in any period, and different individual personalities will have distinctive fear reactions whatever the cultural formula. But are there significant variances in fear standards across place and time, or will further research demonstrate that fear has a similar presence no matter what the social circumstance, varying only in targets and vocabularies? I think the evidence for variance is strong, which is why I am cautious about too readily embracing fear as a contemporary constant. But the need for open-ended inquiry is obvious. Above all, we need a better sense of whether, at least in the Western experience, the nineteenth century mounted an anomalous effort to downplay fear, at least in public culture, or whether such episodes are less uncommon and might even be recaptured by societies today.

Fear is important in contemporary life, certainly in contemporary American life. The growing body of scholarship attached to the emotion suggests the need for more systematic analysis, of the sort that can only develop from coordinated research projects. If fear masters us now, across cultural boundaries, we should know more about how and why. If it has always predominated, despite current historical impressions to the contrary, we should know this as well. The challenge rests, again, fundamentally within the history discipline: we have a current emotional issue about which we need to know more, and we can get a firm handle on this only by looking at the extent of change over time within a comparative framework. Taking on this assessment of fear as an exercise in historical self-understanding could provide unprecedented payoffs for the history of emotion broadly construed. I hope that a group of scholars might commit to this goal, and that at another conference we might share the results.

\section{NOTES}

1 Barry Glassner, The Culture of Fear: Why Americans are Afraid of the Wrong Things, New York: Basic Books, 1999.

2 The 11 September 2001 Digital Archive, http://91 1 digitalarchive.org/stories/details (accessed 12 February 2008).

3 Peter N. Stearns, American Fear: The Causes and Consequences of High Anxiety, New York: Taylor \& Francis, 2006. 


\section{Fear and History}

4 Edmund Lawler, "Fear No Evil in Ads”, B to B 85 (2000), p. 70.

5 Eleftheria Parpis, “Fear Factor”, Adweek Western Edition 512 (2001), p. 11.

6 Christophe Lambert, La Société de la peur, Paris: Plon, 2005.

7 Frank Füredi, Culture of Fear: Risk Taking and the Morality of Low Expectations, rev. ed., London: Continuum, 2002.

8 Stearns, American Fear and Revolutions in Sorrow: American Death Experience and Policy in Global Context, Colorado: Paradigm, 2007.

9 Joanna Bourke, Fear: A Cultural History, Emeryville, CA: Shoemaker Hoard, 2006.

10 See also Jackie Orr, Panic Diaries: A Genealogy of Panic Disorder, Durham, NC: Duke UP, 2006. Orr makes the claim that panic attacks are on the rise.

11 Jean Delumeau, Peur en Occident, XIVe-XVIIle siècles: uné cité assiégée, Paris: Fayard, 1978, and Sin and Fear: The Emergence of a Western Guilt Culture, 13th-18th centuries, New York: St Martin's Press, 1991.

12 Philip Greven, The Protestant Temperament: Patterns of Child-Rearing, Religious Experience, and the Self in Early America, New York: Knopf, 1977. 